\title{
Tailor-Made Electrospun Culture Scaffolds Control Human Neural Progenitor Cell Behavior- Studies on Cellular Migration and Phenotypic Differentiation
}

\author{
Ulrica Englund-Johansson ${ }^{*}$, Eitan Netanyah1,2, Fredrik Johansson² \\ ${ }^{1}$ Department of Clinical Sciences in Lund, Division of Ophthalmology, Lund University, Lund, Sweden \\ ${ }^{2}$ Department of Biology, Section Functional Zoology, Lund University, Lund, Sweden \\ Email: *ulrica.englund_johansson@med.lu.se
}

How to cite this paper: Englund-Johansson, U., Netanyah, E. and Johansson, F. (2017) Human Neural Progenitor Cell Behavior-Studies on Cellular Migration and Phenotypic Differentiation. Journal of Biomaterials and Nanobiotechnology, 8, $1-21$.

http://dx.doi.org/10.4236/jbnb.2017.81001

Received: October 19, 2016

Accepted: December 11, 2016

Published: December 14, 2016

Copyright $\odot 2017$ by authors and Scientific Research Publishing Inc. This work is licensed under the Creative Commons Attribution International License (CC BY 4.0).

http://creativecommons.org/licenses/by/4.0/

\section{Open Access}

\begin{abstract}
In neuroscience research, cell culture systems are essential experimental platforms. It is of great interest to explore in vivo-like culture substrates. We explored how basic properties of neural cells, nuclei polarization, phenotypic differentiation and distribution/migration, were affected by the culture at poly-L-lactic acid (PLLA) fibrous scaffolds, using a multipotent mitogen-expanded human neural progenitor cell (HNPC) line. HNPCs were seeded, at four different surfaces: two different electrospun PLLA $(\mathrm{d}=1.2-1.3 \mu \mathrm{m})$ substrates (parallel or random aligned fibers), and planar PLL- and PLLA surfaces. Nuclei analysis demonstrated a non-directed cellular migration at planar surfaces and random fibers, different from cultures at aligned fibers where HNPCs were oriented parallel with the fibers. At aligned fibers, HNPCs displayed the same capacity for phenotypic differentiation as after culture on the planar surfaces. However, at random fibers, HNPCs showed a significant lower level of phenotypic differentiation compared with cultures at the planar surfaces. A clear trend towards greater neuronal formation at aligned fibers, compared to cultures at random fibers, was noted. We demonstrated that the topography of in vivo-resembling PLLA scaffolds significantly influences HNPC behavior, proven by different migration behavior, phenotypic differentiation potential and nuclei polarization. This knowledge is useful in future exploration of in vivo-resembling neural cell system using electrospun scaffolds.
\end{abstract}

\section{Keywords}

Human Stem Cells, PLLA, Electrospinning, Differentiation, Migration

\section{Introduction}

For proper central nervous system (CNS) development, homeostasis and overall func- 
tion, neural cells normally depend on a close interaction with neighboring cells and the extracellular matrix (ECM), a mixture of structural- and functional proteins. Advanced in vitro cell culture systems mimicking this $3 \mathrm{D}$ environment would most probably generate more relevant initial experimental results, and subsequently a more reliable translation to complex models. This is also a cornerstone for tissue engineering approaches, and electrospinning is a widely-used technique for fabrication of ECM mimicking fibrous scaffolds [1] [2] [3] [4] [5]. Important parameters like fiber diameter, porosity and surface areas can be replicated [1] [6] from many appropriate materials, from both natural and synthetic origin, e.g., natural materials or biodegradable and compatible polymers [1] [7].

Initial work shows that culture a telectrospun fiber scaffolds influence the behavior of a range of neural cell types. Better cell survival, increased differentiation and facilitation of axonal outgrowth in vitro, were described using rodent embryonal cortical-, hippocampal- and retinal cells [8] [9] [10]. Neuronal differentiation from embryonic stem cells including human, was also promoted using fibrous substrates [11] [12]. In peripheral nerve- and spinal cord bioengineering, aligned fiber substrates facilitate and direct neurite outgrowth in vitro, using, e.g., chick [13] or rat dorsal root ganglion [14] [15] and in vivo, for spinal cord injury models [1] [7] [11]-[21]. Other in vivo studies demonstrate that implanted electrospun fibers can interact with neural cells and facilitate tissue regeneration [22], as well as improve delivery and integration of cells grafted to the retina [23]. Although promising, increased understanding on the key physicaland chemical cues of electrospun fibrous substrates for supporting survival- and controlling neural cell behavior is needed for further advancements in many research fields in neuroscience. Indeed, recently, for the first time we reported a significant effect of chemical respective physical cues on post-natal mouse retinal cell behavior using different designed electrospun fibrous scaffolds [24]. Nanotopography per se significantly affected cell morphology, but the chemical cue, i.e. ECM component laminin, was found to be stronger than the physical cue for the orientation of retinal neurites.

A well-acknowledged tool cell assay in neuro-engineering research is expandable embryonal brain-derived precursors. We previously reported efficient use of mitogen-expanded human neural progenitor cell (HNPC) lines in neurorestorative studies, in in vitro and in vivo models of the CNS [25]-[30]. These cells respond to physical cues, with increased cell survival and graft-host integration in vivo by using a nanofiber gel as supporting scaffold [31] [32]. Also, chemical cues affect behavior of such cells, as we presented in studies using a co-culture with explanted brain tissue [29], a specific cocktail for dopaminergic neuron differentiation [25], or by different culture media [30]. NB: In all previous studies, we have used routine planar culture dishes as "base-line" control for, e.g., survival- and phenotypic differentiation capacity.

Therefore, we here wanted to explore how HNPC behavior was affected by in vivoresembling culture surfaces, provided by electrospun PLLA fibrous scaffolds. We examined how fundamental properties of HNPC behavior, including nuclei polarization, phenotypic differentiation and distribution/migration were affected by culture at four different surfaces: two different fibrous $(\mathrm{d}=1.2-1.3 \mu \mathrm{m})$ substrates, i.e., parallel or random aligned fibers, a planar PLLA surface and a traditional PLL-coated glass slide. 
Qualitative studies on distribution/migration and qualitative analysis on phenotypic differentiation and nuclei polarization of the cells were performed, using immunocytochemistry and imaging analysis.

\section{Methods}

\subsection{Fabrication of Culture Substrates}

\subsubsection{Electrospinning}

Poly-L-lactic acid (PLLA), 18,000 - 28,000 g/mol (Sigma Aldrich, St. Louis, USA) was dissolved in chloroform ( $7 \% \mathrm{w} / \mathrm{v})$ and stirred thoroughly to ensure a homogenous solution. The electrospinning device was operated at room temperature in a custom made, ventilated plexiglass hood using a $1 \mathrm{ml}$ syringe (Terumo, Eschborn, Germany) with a blunt, 20 gauge syringe needle (Fisher Scientific, Hampton, USA) driven by a syringe pump (AL-1000, World Precision Instruments, Sarasota, USA). A high voltage supply (HCP35, FUG Elektronik, Rosenheim, Germany) was connected to the needle (positive polarity) and two different targets (grounded) were used to create different fiber morphologies. The spinning parameters used were: accelerating voltage $=24 \mathrm{kV}$, flow rate $=$ $0.5 \mathrm{ml} / \mathrm{h}$, needle-target distance $=15 \mathrm{~cm}$.

For random fibers, a $6 \times 12 \mathrm{~cm}$ stationary steel plate was used as target while a rotating $(5500 \mathrm{rpm}=60 \mathrm{~m} / \mathrm{s})$ thin aluminum wheel $(21 \mathrm{~cm}$ diameter, $3 \mathrm{~cm})$ was used for aligned fibers. In both cases sheets of PLLA film (Goodfellow, Huntingdon, England) were fixed onto the collectors before electrospinning the fibers. The resulting fiber-coated films were removed from the targets, cut into approximately $1 \times 1 \mathrm{~cm}^{2}$ pieces and put in 12-well plates until use. Prior to use the nanofiber substrates were sterilized by incubation in $70 \%$ ethanol for 10 mins at RT, and then dried at RT before use for cell cultures. Samples for scanning electron microscopy (SEM) were sputter-coated (JFC-1300, Anatech Ltd. Denver, NC USA) with $10 \mathrm{~nm}$ gold/platinum prior to observation.

\subsubsection{Control Surfaces}

Two flat culture surfaces were used, i.e., PLLA film (Goodfellow, UK) and PLL-coated glass slides $\left(4 \mu \mathrm{g} / \mathrm{cm}^{2}\right.$, Sigma).

\subsection{Generation and Expansion of the Human Neural Precursor Cell Line}

The human neural progenitor cell line used for this study was originally established by Drs L. Wahlberg, Å. Seiger, and colleagues at the Karolinska University Hospital, Stockholm, Sweden [33]; cell line was kindly provided to us via Prof. A. Björklund (Dept. Exp. Med. Sci., Lund University, Sweden). In brief, the cell line was established from forebrain tissue, isolated and obtained from one 7-week (post conception) human embryo. Cells were cultured as free-floating cell aggregates (neurospheres) in defined DMEM-F12 medium (Invitrogen, Paisley, UK) supplemented with $2.0 \mathrm{mM}$ L-glutamine (Sigma, St. Lois, MI, USA), 0.6\% glucose (Sigma), N2-supplement (Invitrogen), $2.0 \mu \mathrm{g} / \mathrm{ml}$ heparin (Sigma) at $37^{\circ} \mathrm{C}$ in a humidified atmosphere of $5 \% \mathrm{CO}_{2}$. At the initiation of the culture, and thereafter every third day, human basic fibroblast growth factor (hbFGF, $20 \mathrm{ng} / \mathrm{ml}$; Invitrogen), human epidermal growth factor (hEGF, $20 \mathrm{ng} / \mathrm{ml}$; PROSPEC, Rehovot, Israel), and human leukemia inhibitory factor (hLIF, $10 \mathrm{ng} / \mathrm{ml}$; 
PROSPEC) were added to the culture. By using mechanical dissociation, the neuro spheres were passaged every 10 - 14 days and reseeded as single cells at a density of $1 \times$ $10^{5}$ cell/ml. Viable cells (opalescent cells excluding Trypan Blue; Sigma) were counted in a haemocytometer. Cells passaged $11-13$ times were used. The HNPC were plated onto different pre-soaked ( $1 \mathrm{~h}$ in culture medium to make them hydrophilic) substrates as neurospheres taken at day 6 after seeding, and was further cultured with differentiation media, i.e., without hEGF, bFGF and hLIF, and supplemented with $1 \%$ fetal bovine serum (Life Technologies, Europe BV).

\subsection{Seeding and Culture of HNPC}

Spheres, $0.5-1.0 \mathrm{~mm}$ in diameter, were seeded at the center and in a streak at the substrate, with approximately 10 spheres/substrate. The following groups were included, neurospheres seeded on aligned fibers ( $\mathrm{n}=50$ specimens), random fibers ( $\mathrm{n}=50$ specimens), PLLA flat surfaces $(\mathrm{n}=50)$ and PLL-coated glass chamber slides $(\mathrm{n}=12$ specimens). Seedings were performed at least at four independent sessions and days. Starting at 3 days in vitro (DIV), half of the medium volume was changed to fresh medium every $2^{\text {nd }}-3^{\text {rd }}$ day.

\subsection{Immunocytochemistry}

Cells were fixed with $4 \%$ paraformaldehyde (Sigma-Aldrich) in phosphate buffered saline (PBS) for $10 \mathrm{~min}$ and thereafter rinsed $3 \times 10 \mathrm{mins}$ in PBS. The specimens were thereafter pre-incubated in $1 \%$ bovine serum albumin (BSA) in PBS and $0.25 \%$ Triton $\mathrm{X}-100$ for $30 \mathrm{~min}$. Then the cells were incubated with the primary antibodies; rabbit anti-glial fibrillary acidic protein (GFAP, 1:1500 DAKO, Denmark) and goat anti-doublecortin (DCX 1:200, Santa Cruz Biotechnology Inc., Santa Cruz, CA, USA) overnight at $4^{\circ} \mathrm{C}$. After rinsing in PBS specimens were incubated with secondary antibodies; a Texas Red-conjugated donkey anti-rabbit IgG antibody (1:200; Abcam, Cambridge, UK) and a FITC-conjugated donkey anti-goat IgG antibody (1:200; Jackson ImmunoResearch, West Grove, PA, USA). Both primary and secondary antibodies were diluted in PBST containing 1\% BSA. For counterstaining of nuclei and cover-slipping the 4'6-diamidino-2-phenylindole (DAPI)-containing Vectashield mounting medium (Vector Laboratories, Burlingame, CA, USA) was used and the specimens hereafter stored at $-20^{\circ} \mathrm{C}$.

\subsection{Microscopy}

The scanning electron microscope images were acquired using a field emission scanning electron microscope (JEOL JSM-5600 LV) operated typically at an acceleration voltage of $5 \mathrm{kV}$. Fluorescence microscopy was performed on a Nikon Eclipse E800 and the images were analyzed using Imager 2 and Adobe Photoshop (CS5 Extended, ver. 12.0.4 $\times 64)$.

\subsection{Analysis}

\subsubsection{Characterization of Electrospun Fibers}

From SEM images the diameters of $n=20$ fibers per sample $(n=3)$ were measured us- 
ing the software Image J (http://rsb.info.nih.gov/ij/index.html). Fast Fourier transform (FFT) of the SEM images were performed using ImageJ equipped with the plugin "Oval Profile Plot” (http://rsb.info.nih.gov/ij/plugins/oval-profile.html). Here circular areas to minimize edge effects $(n=3)$, from typical SEM images of parallel and random fibers were chosen for FFT. The intensity of the FFT-spectrum was summed radially $\left(360^{\circ}\right)$ using the plugin and plotted for every single angle. Due to the symmetry of the spectra, only values for $0^{\circ}-180^{\circ}$ were used where $90^{\circ}$ indicated perfect alignment. A statistical test (paired T-test) between the FFT-spectrum intensities of the aligned and random fiber-substrates was also done.

\subsubsection{Cell Behavior at the Different Substrates}

Qualitative analysis was made for the seeding success, i.e. attachment of spheres on the respective surface, at two days after seeding. The specimens were analyzed after 2, 5, 10 and 20 days in culture. All quantitative analysis was made at 10 days after seeding.

Nuclei polarization was assessed, by evaluating DAPI-stained nuclei orientation with respect to orientation to fibers in the respective fiber substrate. Nuclei elongation and area was measured from DAPI-stained nuclei using Image J. > 800 nuclei/sphere from 6 spheres/group and taken from $\geq 3$ different substrates was included in the nuclei analysis.

Quantifications of DAPI-, GFAP- and DCX-positive cells ( $\geq 300$ cells/sphere), respectively, were made from six seeded neurospheres taken from different substrates. Cells in the remaining core of the seeded neurosphere were not included and the counting area began directly adjacent to the remaining core.

Qualitative studies were made for the migration, distribution and cellular morphologies of the HNPC after culture at the different substrates ( $\geq 10$ spheres/group taken from at least three different substrates).

Results are given as percentage \pm standard error of the mean (SEM). A value of $\mathrm{p}<$ 0.05 was considered to be statistically significant, with ${ }^{\star} \mathrm{p}<0.05,{ }^{* *} \mathrm{p}<0.01$ and ${ }^{* * *} \mathrm{p}<$ 0.001 .

\section{Results}

\subsection{Fabrication of Electrospun PLLA Fibers}

From SEM-images, the fiber diameter of the aligned electrospun PLLA fibers (Figure $1(\mathrm{~A}))$ was found to be $1.2 \pm 0.5 \mu \mathrm{m}(\mathrm{n}=20)$, while the random PLLA fibers (Figure $1(B))$ had a diameter of $1.3 \pm 0.4 \mu \mathrm{m}(\mathrm{n}=20)$. The FFT-analysis of the alignment confirmed a clear alignment difference between the substrates (Figure 1(C)).

\subsection{Attachment and Survival of Neurospheres}

HNPC were seeded as cellular aggregates (neurospheres), since such, compared to single cells suspensions, have been successfully used in our previous in vivo and in vitro reports for studies including cellular migration. At 2 DIV, neurosphere shad attached on all four surfaces: PLL coated glass chamber slides (100\%), PLLA flat surfaces (100\%), random fibers $86 \%(43 / 50)$ and aligned fibers $90 \%(44 / 49)$. The samples were then equally distributed into the 2, 5, 10 and 20 days survival groups, and at least 5 spheres/ 



Figure 1. Characterization of electrospun PLLA fibers. Scanning electron micrographs of random fibers (A) and aligned fibers (B) clearly show the different fiber arrangement and fiber diameter achieved. The alignment of the different fiber morphologies was quantified using FFT and displayed in a diagram, where a high value indicate many fibers of a certain direction $(\mathrm{C})$.

remaining parts of spheres were found on all specimens up to 20 DIV. Quantification of number of cells surviving was not the scope here.

\subsection{Spatial and Temporal Migration}

Cell phenotype was identified using the marker doublecortin (DCX) for neurons and the marker glial acidic fibrillary protein (GFAP) for glial cells. DCX, a microtubule-associated protein is reported to be expressed from the neuroblast-stage, during neuronal maturation and is normally down-regulated when the neuron is fully mature [34]. GFAP is known to be expressed by human radial glial cells, neural progenitors, astrocytes [35] and also in certain developmental stages of neuronal formation. DCX/GFAP double-positive cells were hence considered as early neurons. The distribution of the cells from the neurospheres on the different topographies was examined at 2 , 5, 10, and 20 days (Figures 2-5).

\subsubsection{Flat Surfaces-Spatial and Temporal Migration}

At 10 DIV on flat surfaces, all cells had migrated out from the sphere and were found widely distributed in the culture chamber (Figure 2(A) and Figure 2(D)). The distribution/migration pattern of the HNPC was indistinguishable between the flat surface substrates; therefore they are presented together. At 2, 5 and 10 DIV a dense mat of 

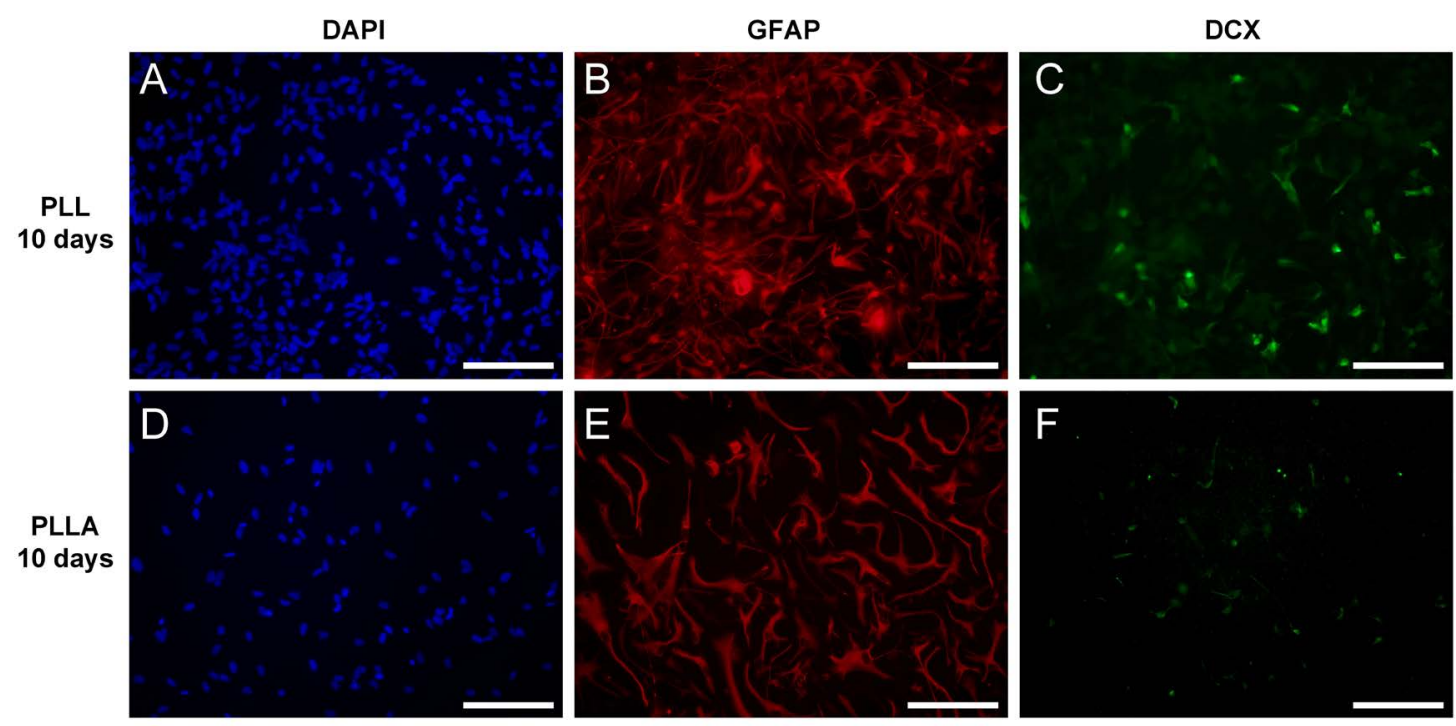

Figure 2. GFAP- and DCX immunocytochemistry for HNPCs at flat PLLA and PLL surfaces. At 10 days after seeding both surfaces were homogenously covered by HNPCs shown by the nuclei labeling with DAPI (A) and (D). Uni-, bi-, and multipolar GFAP+ cell profiles were found. (B) and (E). HNPCs expressing of DCX also displayed uni-, bi-, and multipolar morphologies (C) and (F). Scale bars $=100 \mu \mathrm{m}$.

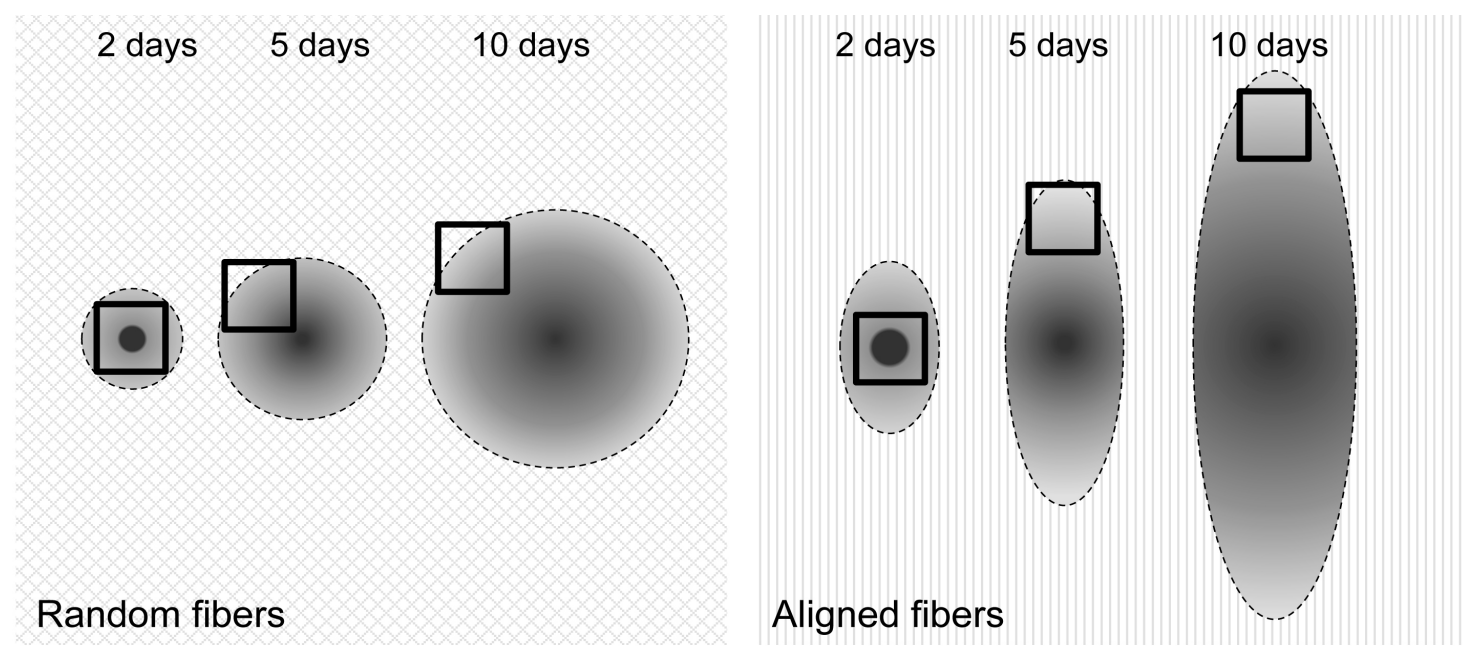

Figure 3. Schematic representation of the cell migration pattern on random (left) and aligned (right) fibers. Note the clearly elongated pattern on the aligned fibers. The black squares show the position of the images shown in Figure 4 and Figure 5.

mainly GFAP-positive (GFAP+) cells were found in a circular distribution pattern with small residues of the sphere in the center (Figure 2(B) and Figure 2(E)). Lagging in time was the migration of a smaller fraction of DCX-positive (DCX+) cells (Figure 2(C) and Figure 2(F)). No residues of the spheres were found in any 10 days and 20 days specimens, and distribution of cells was similar to shorter the shorter time-points.

\subsubsection{Random Fibers-Spatial and Temporal Migration}

HNPC on randomly oriented fibers displayed a very similar distribution/migration pattern as on the flat surfaces. However, the migration rate appeared slower on fiber substrates as larger residues of the spheres remained longer (Figure 3 and Figure 4). 


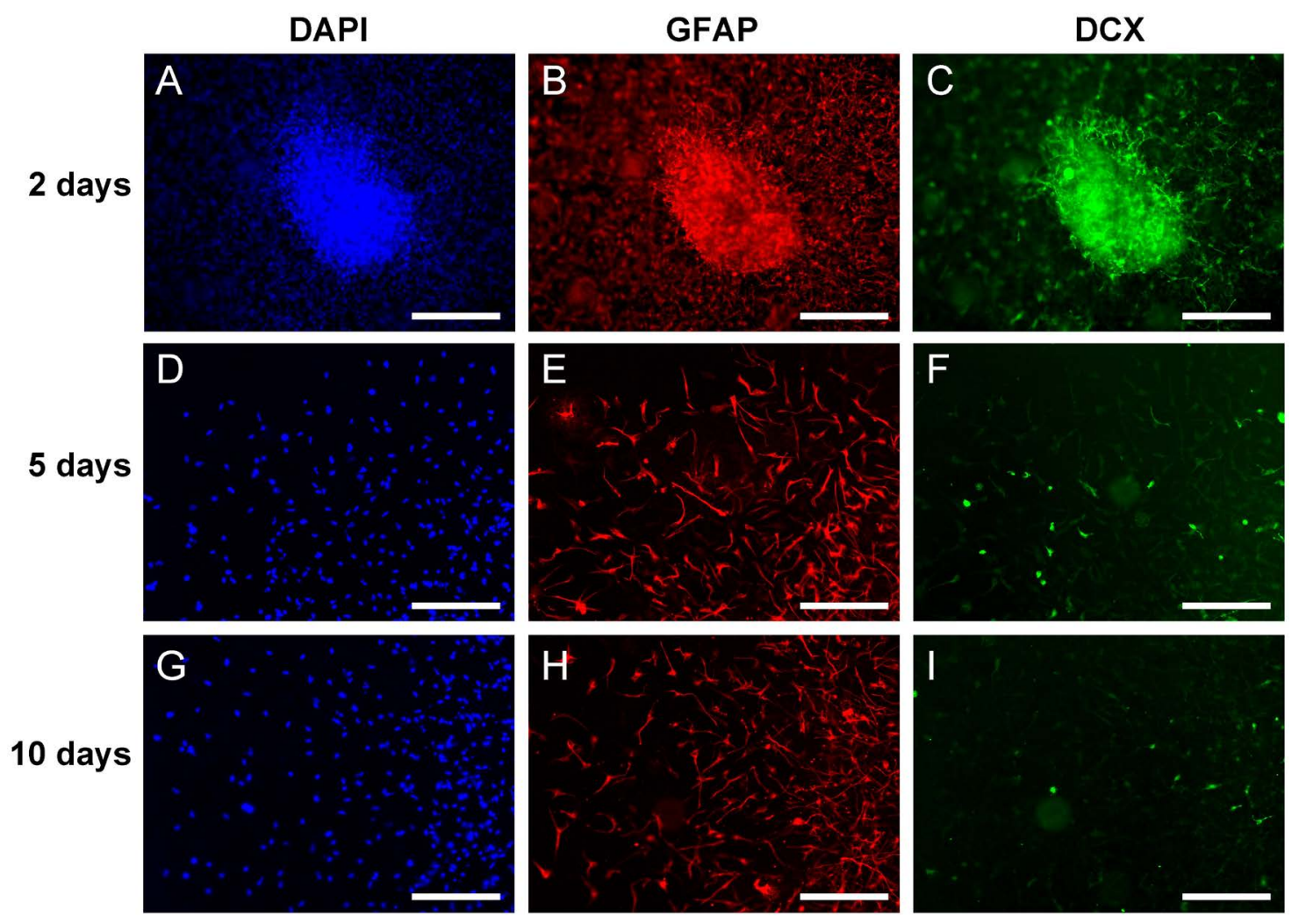

Figure 4. Temporal migration of HNPCs cultured at random PLLA fibers. (A)-(C). At day 2 a residual core of densely packed cells were found (A)-(C). First, the GFAP-expressing cells migrate out from the sphere followed by DCX cells that did not reach the same distance from the sphere center as the GFAP+ cells at 2, 5 or 10 days (cf (B) and (C), (E) and (F), (H) and (I), respectively). (D)-(F). At 5 days the cells had migrated further from the seeding location and formed a larger distribution area and the rests of the neurosphere were rarely seen. The microphotograph is taken in the periphery of the distribution area (D)-(F). (I)-(H). Also at 10 days, the microphotograph is taken in the periphery of the distribution area. Here cells had migrated even further from the seeding location and thus occupied a larger area. At this time-point the DCX+ cells (I) had migrated as far as the GFAP+ cells $(\mathrm{H})$. Scale bars $=100 \mu \mathrm{m}$.

Similar to the flat surfaces at day 2, 5 and 10, a dense mat of mainly GFAP+ cells was found with decreasing residues of the sphere in the center (Figure 3, Figure 4(B), Figure $4(\mathrm{E})$ and Figure $4(\mathrm{H})$ ). At day 2, relative large aggregates of GFAP+ and DCX+ cells was found (Figure 3, Figures 4(A)-(C)), whereas from 5 (Figure 3, Figures 4(D)-(F)) to 10 days (Figure 3, Figures 4(G)-(I)), aggregates of the seeded spheres decreased with time. Also for the cells on randomly oriented fibers, the GFAP+ cells were at any time-point, found more distant from the seeding site as compared to the DCX+ cells that were always found closer to the seeding site (cf. Figure 4(B), Figure 4(C), Figure 4(E), Figure 4(F), Figure 4(H) and Figure 4(I) respectively). Thus, also for the random fiber substrates, the DCX+ neurons migrated slower than the GFAP+ cells. The 10 and 20 days specimens had very similar distribution of cells, and always in a non-directed migration fashion.

\subsubsection{Aligned Fiber Surfaces-Spatial and Temporal Migration}

On aligned fibers the cells migrated out from the spheres and formed an elongated distribution pattern with an increasing area from 2 to 10 DIV (Figure 3, Figure 5). The 


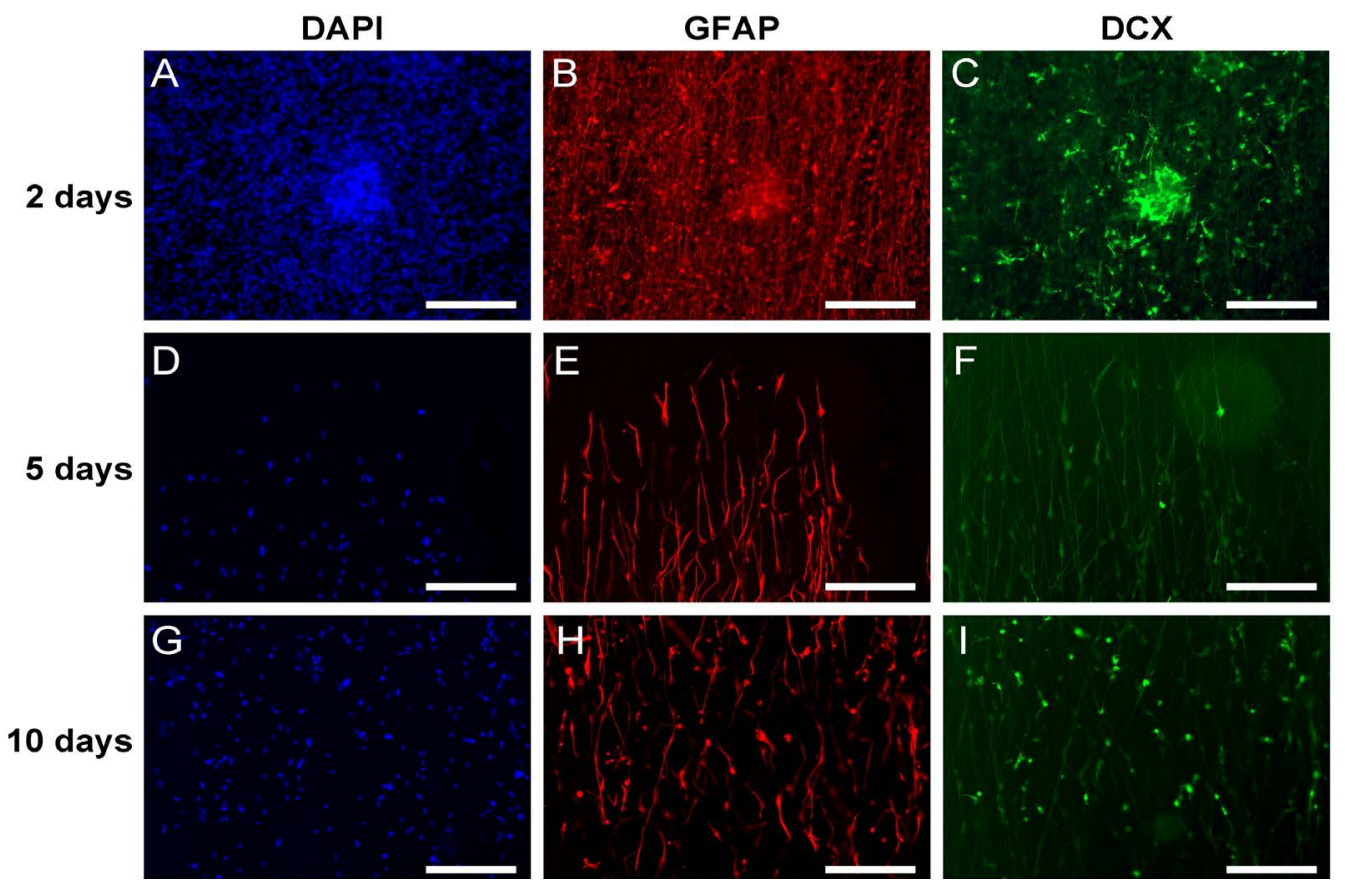

Figure 5. Temporal migration of HNPCs cultured at aligned PLLA fibers. (A)-(C). At day 2 after seeding a core rest of densely packed cells was noted (A)-(C). From the core cells became more and more dispersed. Already at day 2 a large number of especially GFAP+ cells had migrated out from the seeding site and parallel with the fibers (B). DCX+ cells remained close to the seeding site at 2 days (C). (D)-(F). The microphotograph is taken in the periphery of the distribution area and at 5 days the residues from the sphere was gone and the all cells had migrated along the fibers. Primarily the GFAP+ cells migrated along the fibers in straight lines (E), with DCX+ cells associated with them but in a much lower number (F). (H)-(I). The microphotograph is taken in the periphery of the distribution area. At 10 days the numbers of DCX+ cells found at the longer distance from the seeding site was larger than at the shorter survival times (I), and at the same location as the GFAP+ cells (H). Scale bars $=100 \mu \mathrm{m}$.

longer radius in the elliptical formation was always oriented in parallel with the fibers. Cells cultured on aligned fibers showed no clear residues of the spheres at 10 and 20 days, which was the case for cells cultured on the random fiber substrates. At day 10 the cells had migrated from the center placed sphere to the edges of the fiber substrate (i.e. $6 \mathrm{~mm}$ ), and thus a comparison with regard to further migration from day 10 to 20 was not possible. At 2 DIV a relative small aggregate of GFAP+ and DCX+ cells was found (Figure 3, Figures 5(A)-(C)), and the remaining cluster from the seeded spheres at 5 and 10 days decreased over time. Also for HNPCs grown on aligned fibers, at all specific time-points studied, the GFAP+ cells were found at longer distances from the seeding site, compared to the DCX+ (cf. Figure 5(B), Figure 5(C), Figure 5(E), Figure 5(F), Figure 5(H) and Figure 5(I), respectively). The DCX+ cells were most often found to migrate along the GFAP+ cells, and in the same direction according to the apical leading process, typically found in migrating (data not shown).

\subsection{Nuclei Polarization}

Cultures at 10 DIV were analyzed for DAPI-labelled nuclei size, form and orientation (Figures 6(A)-(D)). The nuclei area measurements revealed significantly larger nuclei areas for cells seeded at flat surfaces compared to cells seeded at fiber substrates 


\section{Random fibers}

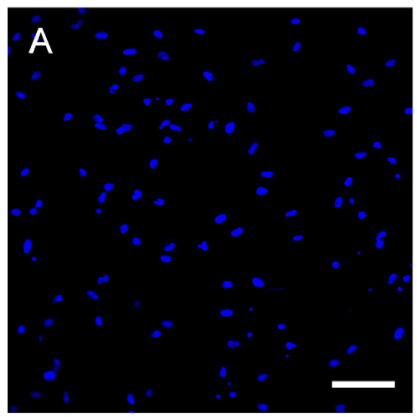

E. Nucleus area

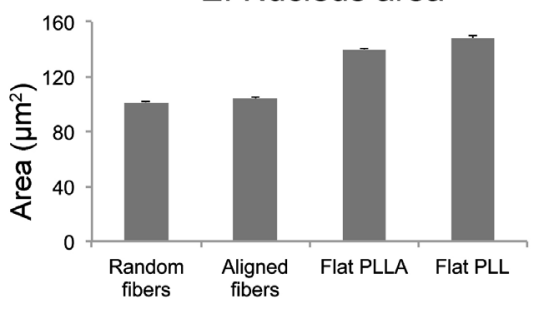

H. Nucleus minor axis

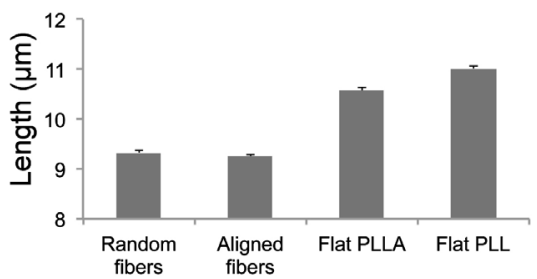

Aligned fibers

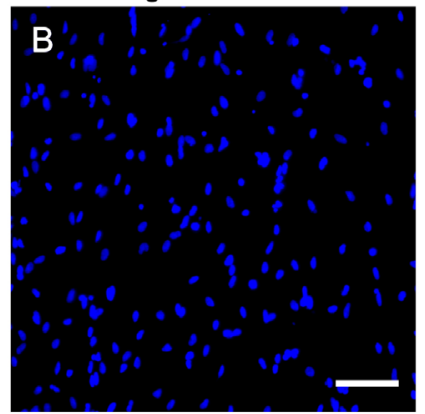

Flat PLLA

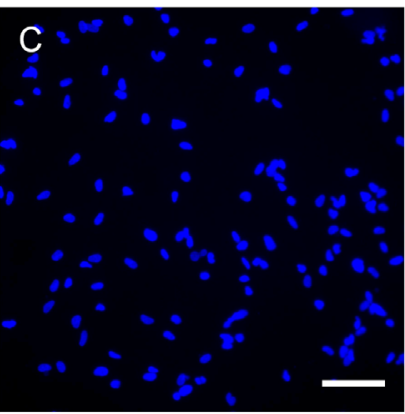

Flat PLL

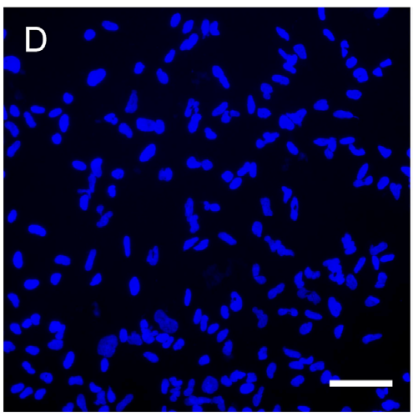

G. Nucleus major axis
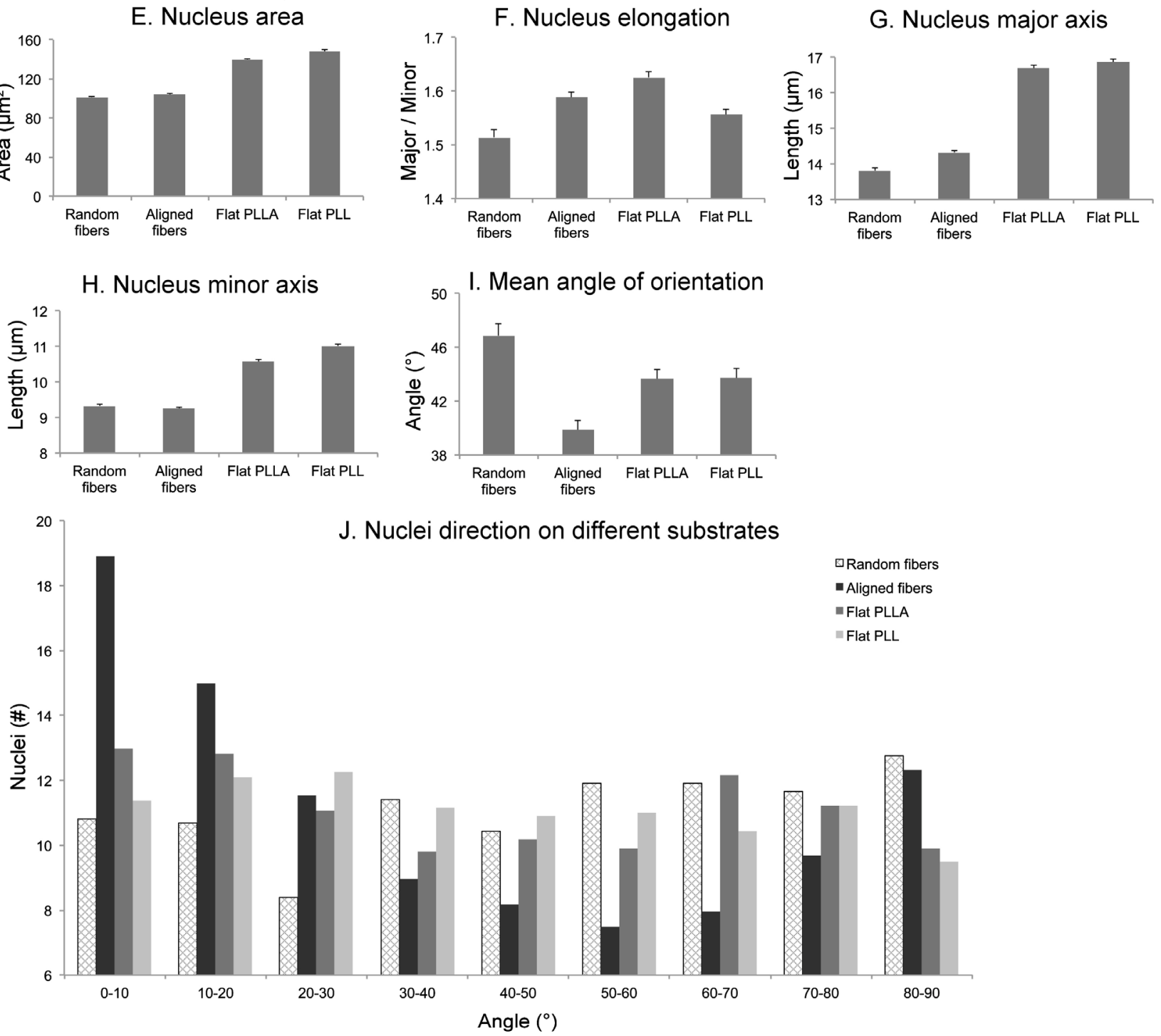

Figure 6. Nuclei alignment of human cells grown at random or aligned PLLA fibers. (A)-(D). Photomicrographs show DAPI labeled cell nuclei at random oriented fibers (A), aligned fibers (B), flat PLLA surface (C) and flat PLL coated glass surface (D). (E). The projected nucleus area was significantly larger for cells grown on flat surfaces as compared to fiber substrates. (F). Elongated nuclei were more common for cells cultured on aligned fibers than random, although also the nuclei on flat PLLA had highly elongated morphology. $(\mathrm{G})$ and $(\mathrm{H})$. Both the major and minor axis of the nuclei was significantly larger for cells grown on flat substrates as compared to the fiber substrates, reflecting the overall mean nucleus area. (I). The alignment of nuclei is significantly different between cells on the aligned fiber substrates as compared to all other substrates. Results are given as mean and SEM, $\mathrm{n}=$ 6/group. Scale bars $=50 \mu \mathrm{m} .\left({ }^{* *} \mathrm{p}<0.01,{ }^{* *} \mathrm{p}<0.001\right)$. 
(Figure 6(E)). Elongated nuclei were more significantly common for cells cultured on aligned fibers than random, although also the nuclei on flat PLLA had highly elongated morphology (Figure 6(F)). Examination of minor- and major axis of the nuclei at planar surfaces showed significantly larger lengths of both parameters compared to cells grown on fiber substrates, reflecting the overall mean nucleus area (Figure $6(\mathrm{G})$ and Figure 6(H)).

The observed non-directed cellular migration, at planar and random fibers, was further supported by the analysis of the nuclei orientation, presented as distribution of cells at different angles from an arbitrary starting point. Here the nuclei angles were evenly distributed from $0^{\circ}-180^{\circ}$, suggesting no preferred direction of the nuclei (Figure 6(I)).

Directed migration at the aligned fibers was also supported nuclei analysis, with a preferred orientation of the nuclei along the fibers, i.e. mostly not differing more than $20^{\circ}$ from the fiber angle (Figure $6(\mathrm{I})$ ). The more elongated nuclei as well as with a longer major axis than nuclei at random fiber substrates suggest a directed migration pattern in parallel with the aligned fibers.

\subsection{Cellular Morphologies and Quantification of GFAP- and DCX-Positive Cells at 10 Weeks}

At 2 DIV at all substrates both DCX- and GFAP- expressing cells displayed a range of different morphologies (Figures 2-5). Here we made a qualitative analysis of the fractions of DCX+- and GFAP+ morphologies, respectively. Then we quantified numbers of GFAP+ and DCX+ cells.

Three major neuronal morphologies were found; 1) round cell bodies with short process/-es, 2) elongated cell bodies with one/two often long processes or 3) round cell bodies with multiple short/long thin processes (Figures $7(\mathrm{~A})-(\mathrm{C})$ ). All three types were observed on the different substrates, but in varying fractions.

Overall, on the flat surfaces, DCX+ cells of the three morphologies were found in equal fractions at all time-points.

At both fibers substrates at early time-points ( 2 and 5 DIV) when cells had migrated moderately, less bipolar DCX+ cells were found. As more extensive cell migration out from the sphere site occurred (10 and 20 DIV), more bipolar DCX+ cells were found. In parallel, multipolar neurons were most frequently found at early time-points at the center of the sphere's original site/residues of the spheres, and increased over time. Elongated DCX+ cells were more typically found on the aligned fibers than on the random oriented fibers (Figure $6(\mathrm{C})$ ). On the aligned fibers, in particular DCX+ cells were found in close contact with the bipolar GFAP+ cells, indicating that the DCX+ cell was migrating along the GFAP+ cell.

GFAP+ cells also displayed primarily three morphologies; 1) large flat cell bodies with multipolar short processes, 2) elongated cell bodies with uni/bipolar often long processes and 3) elongated cell bodies with multiple processes, of which all three types were found on the four different substrates, but in varying degree (Figures $7(D)-(F)$ ). At PLL and PLLA flat surfaces, the majority of GFAP+ cells displayed the large and flat cell profile (Figure 7(D)), and smaller fractions had elongated cell bodies with varying 


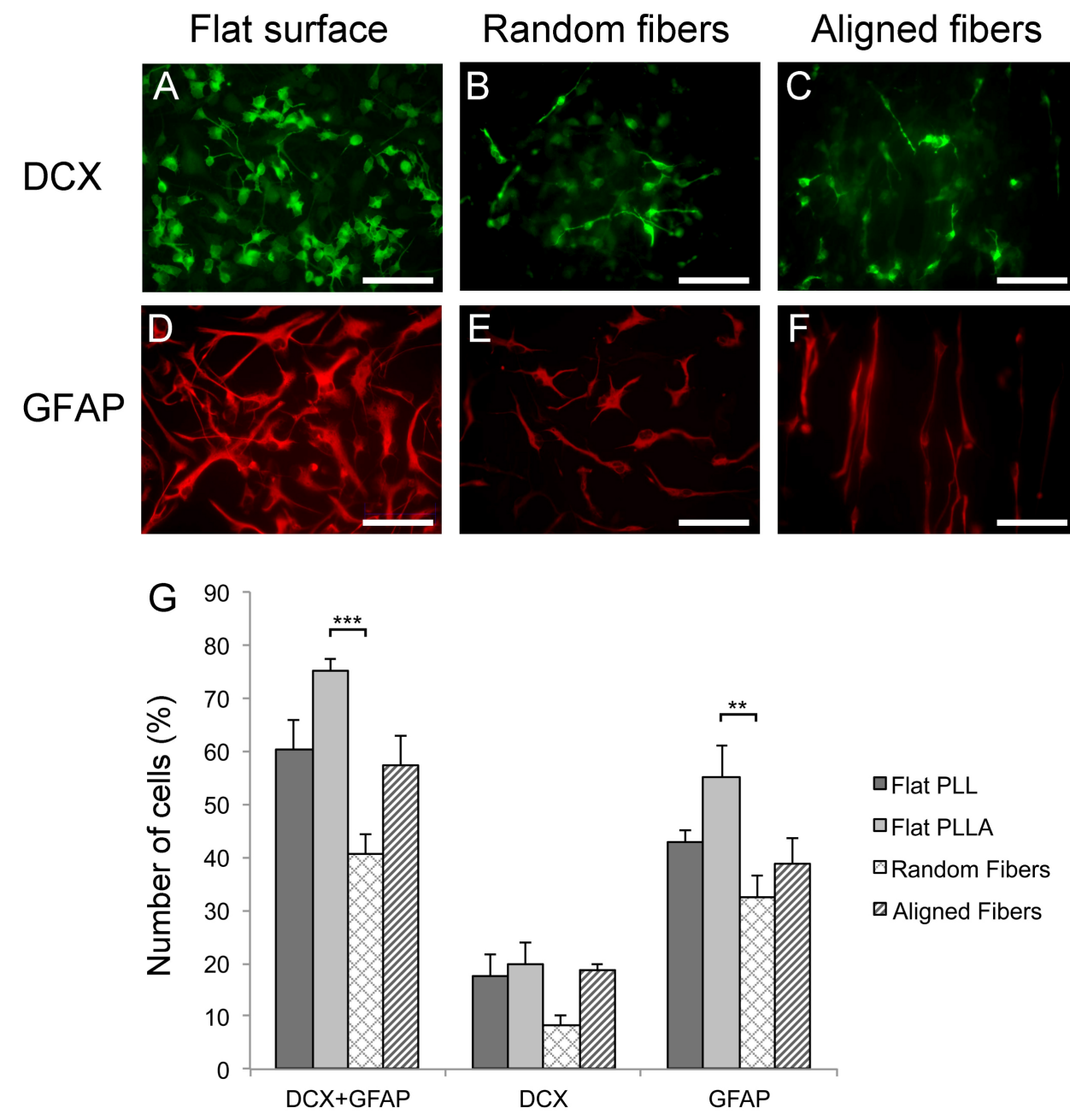

Figure 7. Morphologies of GFAP+- and DCX+ cells and quantification of phenotypic differentiation of HNPC grown at flat PLL- and PLLA surfaces, and random or aligned electrospun nanofiber substrates. (A)-(C). The most common morphologies of DCX-positive cells were round with one process (A), elongated with one/two processes (B) or round with multiple short/long processes (C). (D)-(F). GFAP+ cells displayed primarily three morphologies, large flat with multipolar short processes (D), bipolar elongated (E) and elongated with multiple processes (F). (G). The graph shows total numbers of DCX+- and GFAP+ cells, DCX+cells and GFAP+ cells, presented as percent of total cells (as counted by DAPI staining). Overall cells grown at aligned fibers displayed similar numbers as cells grown at flat surfaces. Note that significantly lower numbers of neurons (DCX+ cells) and total numbers of GFAP+ and DCX+ were found for the random fiber substrate group compared to the flat surface groups (especially cf to PLLA flat control). The differentiation of cells on random fibers shows large variations. Scale bars $=100 \mu \mathrm{m}$. Normalized values as average and SEM is given ( $n=6$ specimens/group), ${ }^{* *} \mathrm{p}<0.01,{ }^{* * *} \mathrm{p}<0.001$.

appearance and numbers of processes. On random fibers, the fraction of flat and large GFAP+ cells was smaller than the PLL- and PLLA groups, and a larger fraction of elongated cells was observed (Figure 7(E)). Typically the more elongated GFAP+ cells were located in the periphery of the distribution area. In parallel, elongated GFAP+ cells were found in the periphery on aligned fibers, and were the above all most common cell-type found here (Figure 7(F)). Flat and large GFAP+ cells were only occasionally found at aligned fibers. 
Quantification of numbers of DCX+- and GFAP+ cells, respectively, were performed (Figure $7(\mathrm{G})$ ). At the flat surfaces higher total numbers of DCX+ and GFAP+ cells were found for PLLA compared to PLL, but no significant difference were found between the groups (cf. 75\% (PLLA) to 60\% (PLL)). The total number of DCX+ and GFAP+ cells after culture at aligned and random fibers was, 57\% and 41\%, respectively. There was a significant larger fraction $(\mathrm{p}<0.001)$ of DCX+ and GFAP+ at the flat PLLA surface compared to the fraction found at the random fiber substrates.

Compared to the flat surface (PLLA), a similar numbers of neurons was found at aligned fibers (cf. $19 \%$ to $20 \%, \mathrm{n}=6$ ), but $<50 \%$ at random fibers (cf. $8 \%$ and $20 \%, \mathrm{n}=$ 6). However, there was no significant difference between numbers of DCX+ cells on flat PLLA and random fiber substrates. The large variance in the numbers of DCX+cells found at the random fiber substrates may explain this result.

A lower number of GFAP+ cells were found when cells were cultured on the fiber substrates, with $32 \%$ for the random fibers and $39 \%$ for the aligned, as compared to $55 \%$ GFAP+ cells found on the PLLA flat surface. There was a significantly lower number of GFAP+ cells on the random fibers $(\mathrm{p}<0.01)$, but not on the aligned fibers compared to PLLA flat surface.

\section{Discussion}

Here we demonstrate that non-functionalized PLLA electrospun fibrous scaffolds support survival, and can guide migration and promote differentiation of human embryonal brain-derived progenitors. These cells represent a heterogeneous population of neural stem- and progenitor cells, are non-immortalized and can be stable expanded into extensive numbers in the presence of mitogens with maintained multipotency, i.e. ability to form neurons, glia and oligodendrocytes [33]. Thus, the current used HNPC line is a relevant source for studies on human brain development (especially forebrain) but also as a screening cell assay in $2 \mathrm{D}$ or $3 \mathrm{D}$ cultures of novel treatment paradigms or for testing neurotoxicity.

Today extensive attention is focused at developing 3D neural cell culture devices in drug discovery and tissue engineering, due to their apparent advantages in providing more physiologically relevant information and more predictive data for in vivo tests.

In the brain, normal cells experience a three-dimensional environment, completely surrounded by other cells, membranes, fibrous layers, and adhesion proteins. Recent advancements in development of novel in vivo mimicking culture systems, holds great promise for new insights into CNS development, function and disease pathologies. Early studies using cell-aggregate cultures and hydrogels to mimic the $3 \mathrm{D}$ environment, showed longer survival, different differentiation pattern, longer neurite outgrowth and formation of higher density networks compared to traditional 2D cell cultures (e.g., [36] [37]). Encouraged by this other culture systems, mainly sponges and fibers made from both synthetic and natural materials, and combinations of both, were fabricated (e.g., [38]).

The current used technique, electrospinning, is an advantageous method for fabrication of scaffolds where the major physical, chemical and mechanical properties of the ECM can be replicated and modified [39]. 


\subsection{Attachment and Survival of HNPC at PLLA Substrates}

A necessity for the success of a biomaterial is good survival of the cells that come in contact with it. In agreement with others using rodent cortical- and hippocampal-derived neural cells and the biodegradable and widely used biomaterials: PLGA, PCL and PLLA [8] [9] [10], the human cells used here displayed very good survival at the surfaces made of PLLA. Since we chose to use neurospheres as a seeding method it was not possible to quantify exact numbers of cells surviving the culture period. However, by counting numbers of spheres at two days after seeding and the at the end of the culture period (i.e. 20 days) we report a $86 \%$ - 90\% survival of numbers of seeded spheres (judged by the obvious residual of the sphere)in the groups seeded at fibers compared to the $100 \%$ survival at the flat substrates. The small decrease in numbers of spheres found at the fibers, compared to at the flat surfaces, may be explained by the larger potential contact area provided by the flat substrate area compared to the substrates made from random and aligned fibers, respectively. Further detailed studies on the survival by counting of single seeded cells or by using viability assays (e.g. colometric assays with MTT or alamar blue) for measuring cell respiration, is needed for investigating this aspect further. Here it was out of the scope to study the proliferation level of the HNPC after seeding, which can be easily performed by BrdU-incorporation studies or by labeling with markers specific for dividing cells, such as Ki67 [27]. It may be suggested that proliferation may continue after seeding at the surfaces in media without the mitogens and $1 \%$ serum added (i.e. "differentiation media"), as detected when similar cells were differentiated in vitro [40] or transplanted in vivo to the rodent brain [26] [27].

\subsection{Topography Influence HNPC Nuclei Alignment and Migration Rate and Extension}

In correspondence with our results, others have shown that primary neurons polarize in parallel with fiber orientation [19]. In the CNS, neuronal networks are highly complex and ordered structures with neurons extending often long axons/dendrites in a directed fashion.

We describe that the nanotopography, indeed, can direct the cellular migration and nuclei alignment, using random and aligned fibers substrates. Neuronal migration is a fundamental process that decides the final location of neurons in the nervous system and creates the basis for neuronal circuitry formation [41] [42]. The current used HNPC cell line is originating from the embryonic 7 week forebrain, and thus consists of neuronal- and glial precursor cells of above all the cortex, striatum and olfactory bulb. Notably, the neurons generated in these regions are known to migrate by significantly different modes to their final position; radially in the developing cortex via guidance by radial glia, tangentially and perpendicular to radial glia from the ganglionic eminences to final locations, e.g., in the cortex and in cell chain formations from the subventricular zone (SVZ) along the rostral migratory stream to the olfactory bulb. Radial glial cells serve several important functions in the patterning and differentiation of the developing CNS, by contributing to the generation, migration and also the specification and/or formation of neuronal subpopulations [43]. 
Primate (including human) radial glia expresses GFAP and can stretch over several $\mathrm{mm}$ in the developing cortex. Our results clearly suggest that the 7 week old HNPC line maintain some of the developmental mechanisms described for especially the cortex, exemplified here using the aligned fibers and seen by the migration of first bipolar GFAP+ cells and later newly formed neurons (DCX+ cells) migrating along these. In addition, the cell profile of neurons migrating along radial glial cells have been described as typically unipolar, a cell morphology frequently found here at the aligned fiber substrates [44]. It has been suggested that branching processes is the default morphology for migrating neurons, which is suppressed in radial glia migration [45]. This further supports our finding that DCX+ cells at aligned fibers rarely displayed multipolar cell profiles and the majority of the elongated DCX+cells possessed single processes. In agreement, where less "radial-glia" like cells were found, i.e. at the random fibers larger fractions DCX+ cells with multipolar profiles and elongated cell bodies with branching processes were found.

A previous report demonstrates control of polarization, using computerized nuclei analysis, of rodent embryonic hippocampal neurons by using different topographies made by electrospun fibers [9]. By using the same analysis method, we can here confirm that also HNPC nuclei indeed align with the orientation electrospun fibers. Moreover, the entire nuclei adopted to the type of fiber orientation, exemplified by the significantly larger number of elongated nuclei (reflecting the uni- and bipolar DCX+ cells) found at the aligned fibers cf. to the random oriented counterpart. In addition, we found a significant different migration mode between HNPC cultured at random and aligned fibers, respectively. Random fibers generated a non-directed migration whereas aligned fibers promoted migration along the fibers.

Moreover, it was obvious that the HNPC migrated at a higher rate at the aligned fibers compared to at the random fibers. This is in line with a recent study describing a three-fold faster migration of keratinocytes along a straight line compared to at a flat surface [46].

Taken together, our results strongly suggest that subcellular features, indeed, can be used to control migration rate and direction of human brain-derived progenitors. In further studies, the current protocols may be utilized for region-specific analysis of the neurons as well as more in-depth studies of the sequential migration for the supposed cortical progenitors.

\subsection{Topography Influence HNPC Phenotypic Differentiation}

It has been demonstrated that cell responses in $3 \mathrm{D}$ cultures are more similar to in vivo behavior compared to planar culture. These spatial and physical aspects in $3 \mathrm{D}$ cultures are reported to affect the signal transduction from the outside to the inside of cells, and ultimately influence gene expression and cellular behavior. Again, the HNPC line used here is an excellent tool cells for studying different parameters that can control phenotypic differentiation. Importantly, across different laboratories very similar results have been reported on the fraction of neurons and glia generated after moderate to high numbers of passages, i.e. about $20 \%$ and $40 \%$ - 50\%, respectively [25] [33] [47] [48] [49]. Up-to-date phenotypic differentiation of neural stem cells has mainly been con- 
trolled by using diffusible factors added to the cell culture medium, e.g. dopaminergic neurons can efficiently be derived from human embryonic stem cells (hESC), with a proven significant functional effect after transplantation to a rat model of PD [50]. A very limited number of studies have explored the impact on features in the micro-nanometer scale for controlling differentiation of neural progenitor cells, and the recent studies have all used rodent cells. However, Shahbazi et al. demonstrated that a three-dimensional nanofibrillar scaffold is permissive for neuronal differentiation ofhESC [51].

Here we demonstrate that culture of HNPC at aligned fibers is more permissive for overall differentiation into GFAP+ and DCX+ cells, compared to use of random oriented fibers. This is important knowledge if e.g. the cell-scaffolds are being further explored for transplantation therapies aiming at cellular replacement.

Furthermore, the orientation of the fibers had a clear impact on the cellular morphologies, i.e., more uni- and bipolar cells found on the aligned fibers cf. to a larger fraction of multipolar cells at random fibers. This regularly described alignment, along e.g., fiber structures, is a case of contact guidance. This is believed to be due to restrictions in attachment sites and thus focal contact shape and size [52] [53] [54], together with restrictions due to the rigidity of the cytoskeleton [55] [56]. Hence, on an anisotropy structure like aligned fibers, there will be elongated aligned focal contacts that in turn dictates in what direction the cytoskeleton forces can act. The anisotropically spread forces typically induce an elongated cellular morphology, as presented by the HNPC in this case. In sharp contrast, on flat surfaces with no restrictions in attachment sites, cells typically display a more round and flat morphology due to numerous focal adhesions (=larger-attachment points) stretching the cell in all directions along the plane of the surface, as also found here.

Finally, cell cultured on randomly oriented fibers, display a combination of the above: isotopically restricted attachment points, resulting in less flat, round or multipolar cells, as shown in this study. Nevertheless, it should also be noted that some cell types, often central nervous system neurons have been demonstrated to line up perpendicular to aligned structures i.e. grooves and ridges [57] [58]. This may be the reason of the unexpectedly high number of cells aligned close to $90^{\circ}$ from the fiber direction, while very few where found to align between $20^{\circ}$ and $70^{\circ}$. This may be a differentiated subpopulation displaying perpendicular orientation preferences.

The fact that the different fiber substrates generate different morphologies of neurons, lead to the question whether a specific substrate have the potential to enrich for a regions-specific neuronal population. By using region-specific neuronal markers of the cortex, striatum and OB such analysis this question can be addressed in future studies. If this is the case, the use of diffusible factors may not be needed to direct subtype neuronal differentiation.

Our data clearly demonstrate the appearance of different types of glial cells, based on morphological analysis. We believe that radial-glial like GFAP+ cells are formed preferable at the aligned fibers. GFAP is known to be expressed by human radial glial cells and the bipolar cell profiles with often DCX neurons migrating along them, further suggesting this identity. Notably, the flat PLLA control-substrates displayed more over- 
all differentiation for both glial- and neuronal differentiation as compared to standard flat PLL coated glass surfaces, or the two fiber substrates. Here, the quantitative differentiation results from PLL flat surfaces and aligned fibers were very similar in this respect. The finding that cultures at the random fiber substrates showed the lowest differentiation potential, or slow down this process, indicate that such structures could be utilized for keeping stem cell-ness, a task otherwise usually solved by a feeder-layer of suitable cells.

In summary, the polymer PLLA itself is more permissive for differentiation of the HNPCs compared to standard used PLL coating of glass chamber slides. Our current study presents an interesting model system for studying crucial factors for the migration and morphological development of forebrain neurons in a spatial and temporal fashion. In further studies it is of great interest to in detail investigate the functional development of the HNPC-derived neurons, by studying e.g. expression of markers for late neuronal differentiation, such as MAP-2 and neurofilament as well as for synaptic formation (e.g., the markers synaptophysin and SV2 [29]. Studies of electrical activity are also needed, and Bourke at al previously reported maintained electrical activity over time in rodent CNS-derived neurons, using patch-clamp techniques [8].

\section{Conclusion}

By using two distinctly different topographies of electrospun PLLA fibrous scaffolds, we report that the physical cues significantly affect basic human brain progenitor behavior, including migration and phenotypic differentiation potential. We strongly believe that the current presented simple non-functionalized HNPC-fibrous scaffold system can serve as an excellent model in further studies exploring topics including brain development and function, neurotoxicity, and in advancement of cellular replacement therapies.

\section{Acknowledgements}

This study was funded by: The Medical faculty, Lund University (UEJ), Crafoord Foundation (UEJ, FJ), Royal Physiographic Society in Lund (UEJ, FJ), NanoLund (FJ), Olle and Signe Engqvist Foundation (UEJ) and Magnus Bergvall Foundation (UEJ).

\section{References}

[1] Agarwal, S., Wendorff, J.H. and Greiner, A. (2009) Progress in the Field of Electrospinning for Tissue Engineering Applications. Advanced Materials, 21, 3343-3351. https://doi.org/10.1002/adma.200803092

[2] Dalby, M.J., Gadegaard, N. and Oreffo, R.O. (2014) Harnessing Nanotopography and Integrin-Matrix Interactions to Influence Stem Cell Fate. Nature Materials, 13, 558-569. https://doi.org/10.1038/nmat3980

[3] Kang, K., Kim, M.H., Park, M. and Choi, I.S. (2014) Neurons on Nanotopographies: Behavioral Responses and Biological Implications. Journal of Nanoscience and Nanotechnology, 14, 513-521. https://doi.org/10.1166/jnn.2014.8764

[4] Tsimbouri, P., Gadegaard, N., Burgess, K., White, K., Reynolds, P., Herzyk, P., et al. (2014) Nanotopographical Effects on Mesenchymal Stem Cell Morphology and Phenotype. Journal of Cellular Biochemistry, 115, 380-390. https://doi.org/10.1002/jcb.24673 
[5] Vidu, R., Rahman, M., Mahmoudi, M., Enachescu, M., Poteca, T.D. and Opris, I. (2014) Nanostructures: A Platform for Brain Repair and Augmentation. Frontiers in Systems Neuroscience, 8, 91. https://doi.org/10.3389/fnsys.2014.00091

[6] Vasita, R. and Katti, D.S. (2006) Nanofibers and Their Applications in Tissue Engineering. International Journal of Nanomedicine, 1, 15-30. https://doi.org/10.2147/nano.2006.1.1.15

[7] Braghirolli, D.I., Steffens, D. and Pranke, P. (2014) Electrospinning for Regenerative Medicine: A Review of the Main Topics. Drug Discovery Today, 19, 743-753. https://doi.org/10.1016/j.drudis.2014.03.024

[8] Bourke, J.L., Coleman, H.A., Pham, V., Forsythe, J.S. and Parkington, H.C. (2014) Neuronal Electrophysiological Function and Control of Neurite Outgrowth on Electrospun Polymer Nanofibers Are Cell Type Dependent. Tissue Engineering Part A, 20, 1089-1095. https://doi.org/10.1089/ten.tea.2013.0295

[9] Lee, J.Y., Bashur, C.A., Gomez, N., Goldstein, A.S. and Schmidt, C.E. (2010) Enhanced Polarization of Embryonic Hippocampal Neurons on Micron Scale Electrospun Fibers. Journal of Biomedical Materials Research Part A, 92, 1398-1406.

[10] Nisbet, D.R., Pattanawong, S., Ritchie, N.E., Shen, W., Finkelstein, D.I., Horne, M.K., et al. (2007) Interaction of Embryonic Cortical Neurons on Nanofibrous Scaffolds for Neural Tissue Engineering. Journal of Neural Engineering, 4, 35-41. https://doi.org/10.1088/1741-2560/4/2/004

[11] Rahjouei, A., Kiani, S., Zahabi, A., Mehrjardi, N.Z., Hashemi, M., et al. (2011) Interactions of Human Embryonic Stem Cell-Derived Neural Progenitors with an Electrospun Nanofibrillar Surface in Vitro. The International Journal of Artificial Organs, 34, 559-570.

[12] Xie, J., Willerth, S.M., Li, X., Macewan, M.R., Rader, A., Sakiyama-Elbert, S.E., et al. (2009) The Differentiation of Embryonic Stem Cells Seeded on Electrospun Nanofibers into Neural Lineages. Biomaterials, 30, 354-362. https://doi.org/10.1016/j.biomaterials.2008.09.046

[13] Schnell, E., Klinkhammer, K., Balzer, S., Brook, G., Klee, D., Dalton, P., et al. (2007) Guidance of Glial Cell Migration and Axonal Growth on Electrospun Nanofibers of Poly-Epsilon-Caprolactone and a Collagen/Poly-Epsilon-Caprolactone Blend. Biomaterials, 28, 30123025. https://doi.org/10.1016/j.biomaterials.2007.03.009

[14] Corey, J.M., Gertz, C.C., Wang, B.S., Birrell, L.K., Johnson, S.L., Martin, D.C., et al. (2008) The Design of Electrospun PLLA Nanofiber Scaffolds Compatible with Serum-Free Growth of Primary Motor and Sensory Neurons. Acta Biomaterialia, 4, 863-875. https://doi.org/10.1016/j.actbio.2008.02.020

[15] Wang, H.B., Mullins, M.E., Cregg, J.M., Hurtado, A., Oudega, M., Trombley, M.T., et al. (2009) Creation of Highly Aligned Electrospun Poly-L-Lactic Acid Fibers for Nerve Regeneration Applications. Journal of Neural Engineering, 6, Article ID: 016001. https://doi.org/10.1088/1741-2560/6/1/016001

[16] Biazar, E., Khorasani, M.T., Montazeri, N., Pourshamsian, K., Daliri, M., et al. (2010) Types of Neural Guides and Using Nanotechnology for Peripheral Nerve Reconstruction. International Journal of Nanomedicine, 5, 839-852. https://doi.org/10.2147/IJN.S11883

[17] Gupta, D., Venugopal, J., Prabhakaran, M.P., Giri Dev, V.R., Low, S., Choon, A.T., et al. (2009) Aligned and Random Nanofibrous Substrate for the in Vitro Culture of Schwann Cells for Neural Tissue Engineering. Acta Biomaterialia, 5, 2560-2569.

https://doi.org/10.1016/j.actbio.2009.01.039

[18] Kim, Y.T., Haftel, V.K., Kumar, S. and Bellamkonda, R.V. (2008) The Role of Aligned Polymer Fiber-Based Constructs in the Bridging of Long Peripheral Nerve Gaps. Biomaterials, 29, 3117-3127. https://doi.org/10.1016/j.biomaterials.2008.03.042

[19] Leach, M.K., Feng, Z.Q., Gertz, C.C., Tuck, S.J., Regan, T.M., Naim, Y., et al. (2011) The Culture of Primary Motor and Sensory Neurons in Defined Media on Electrospun Poly-L- 
Lactide Nanofiber Scaffolds. Journal of Visualized Experiments, 48, e2389. https://doi.org/10.3791/2389

[20] Liu, J.J., Wang, C.Y., Wang, J.G., Ruan, H.J. and Fan, C.Y. (2011) Peripheral Nerve Regeneration Using Composite Poly (Lactic Acid-Caprolactone)/Nerve Growth Factor Conduits Prepared by Coaxial Electrospinning. Journal of Biomedical Materials Research Part A, 96, 13-20. https://doi.org/10.1002/jbm.a.32946

[21] Zamani, F., Amani-Tehran, M., Latifi, M., Shokrgozar, M.A. and Zaminy, A. (2014) Promotion of Spinal Cord Axon Regeneration by 3D Nanofibrous Core-Sheath Scaffolds. Journal of Biomedical Materials Research Part A, 102, 506-513. https://doi.org/10.1002/jbm.a.34703

[22] Nisbet, D.R., Rodda, A.E., Horne, M.K., Forsythe, J.S. and Finkelstein, D.I. (2009) Neurite Infiltration and Cellular Response to Electrospun Polycaprolactone Scaffolds Implanted into the Brain. Biomaterials, 30, 4573-4580. https://doi.org/10.1016/j.biomaterials.2009.05.011

[23] Kador, K.E. and Goldberg, J.L. (2012) Scaffolds and Stem Cells: Delivery of Cell Transplants for Retinal Degenerations. Expert Review of Ophthalmology, 7, 459-470. https://doi.org/10.1586/eop.12.56

[24] Zalis, M.C., Johansson, S., Johansson, F. and Johansson, U.E. (2016) Exploration of Physical and Chemical Cues on Retinal Cell Fate. Molecular and Cellular Neuroscience, 75, 122-132. https://doi.org/10.1016/j.mcn.2016.07.006

[25] Christophersen, N.S., Meijer, X., Jorgensen, J.R., Englund, U., Gronborg, M., Seiger, Å., et al. (2006) Induction of Dopaminergic Neurons from Growth Factor Expanded Neural Stem/Progenitor Cell Cultures Derived from Human First Trimester Forebrain. Brain Research Bulletin, 70, 457-466. https://doi.org/10.1016/j.brainresbull.2006.07.001

[26] Englund, U., Bjorklund, A. and Wictorin, K. (2002) Migration Patterns and Phenotypic Differentiation of Long-Term Expanded Human Neural Progenitor Cells after Transplantation into the Adult Rat Brain. Developmental Brain Research, 134, 123-141. https://doi.org/10.1016/S0165-3806(01)00330-3

[27] Englund, U., Fricker-Gates, R.A., Lundberg, C., Bjorklund, A. and Wictorin, K. (2002) Transplantation of Human Neural Progenitor Cells into the Neonatal Rat Brain: Extensive Migration and Differentiation with Long-Distance Axonal Projections. Experimental Neurology, 173, 1-21. https://doi.org/10.1006/exnr.2001.7750

[28] Englund-Johansson, U., Mohlin, C., Liljekvist-Soltic, I., Ekstrom, P. and Johansson, K. (2010) Human Neural Progenitor Cells Promote Photoreceptor Survival in Retinal Explants. Experimental Eye Research, 90, 292-299. https://doi.org/10.1016/j.exer.2009.11.005

[29] Novozhilova, E., Olivius, P., Siratirakun, P., Lundberg, C. and Englund-Johansson, U. (2013) Neuronal Differentiation and Extensive Migration of Human Neural Precursor Cells following Co-Culture with Rat Auditory Brainstem Slices. PLOS ONE, 8, e57301. https://doi.org/10.1371/journal.pone.0057301

[30] Parmar, M., Skogh, C. and Englund, U. (2003) A Transplantation Study of Expanded Human Embryonic Forebrain Precursors: Evidence for Selection of a Specific Progenitor Population. Molecular and Cellular Neuroscience, 23, 531-543. https://doi.org/10.1016/S1044-7431(03)00097-6

[31] Jiao, Y., Palmgren, B., Novozhilova, E., Englund Johansson, U., Spieles-Engemann, A.L., et al. (2014) BDNF Increases Survival and Neuronal Differentiation of Human Neural Precursor Cells Cotransplanted with a Nanofiber Gel to the Auditory Nerve in a Rat Model of Neuronal Damage. BioMed Research International, 2014, Article ID: 356415. https://doi.org/10.1155/2014/356415

[32] Kale, A., Novozhilova, E., Englund-Johansson, U., Stupp, S., Palmgren, B. and Olivius, P. (2014) Exogenous BDNF and Chondroitinase ABC Consisted Biomimetic Microenvironment Regulates Survival, Migration and Differentiation of Human Neural Progenitor Cells 
Transplanted into a Rat Auditory Nerve. Neuroscience \& Medicine, 5, 86-100. https://doi.org/10.4236/nm.2014.52012

[33] Carpenter, M.K., Cui, X., Hu, Z.Y., Jackson, J., Sherman, S., Seiger, Å., et al. (1999) In Vitro Expansion of a Multipotent Population of Human Neural Progenitor Cells. Experimental Neurology, 158, 265-278. https://doi.org/10.1006/exnr.1999.7098

[34] Niu, W., Zang, T., Zou, Y., Fang, S., Smith, D.K., Bachoo, R., et al. (2013) In Vivo Reprogramming of Astrocytes to Neuroblasts in the Adult Brain. Nature Cell Biology, 15, 11641175. https://doi.org/10.1038/ncb2843

[35] Bramanti, V., Tomassoni, D., Avitabile, M., Amenta, F. and Avola, R. (2010) Biomarkers of Glial Cell Proliferation and Differentiation in Culture. Frontiers in Bioscience (Scholar Edition), 2, 558-570.

[36] Hwang, C.M., Sant, S., Masaeli, M., Kachouie, N.N., Zamanian, B., et al. (2010) Fabrication of Three-Dimensional Porous Cell-Laden Hydrogel for Tissue Engineering. Biofabrication, 2, Article ID: 035003. https://doi.org/10.1088/1758-5082/2/3/035003

[37] Pardo, B. and Honegger, P. (2000) Differentiation of Rat Striatal Embryonic Stem Cells in Vitro: Monolayer Culture vs. Three-Dimensional Coculture with Differentiated Brain Cells. Journal of Neuroscience Research, 59, 504-512. https://doi.org/10.1002/(SICI)1097-4547(20000215)59:4<504::AID-JNR5>3.0.CO;2-N

[38] Li, M., Mondrinos, M.J., Chen, X. and Lelkes, P.I. (2005) Electrospun Blends of Natural and Synthetic Polymers as Scaffolds for Tissue Engineering. Conference Proceedings of IEEE Engineering in Medicine and Biology Society, 6, 5858-5861.

[39] Lim, S.H. and Mao, H.Q. (2009) Electrospun Scaffolds for Stem Cell Engineering. Advanced Drug Delivery Reviews, 61, 1084-1096. https://doi.org/10.1016/j.addr.2009.07.011

[40] Ostenfeld, T., Joly, E., Tai, Y.T., Peters, A., Caldwell, M., et al. (2002) Regional Specification of Rodent and Human Neurospheres. Developmental Brain Research, 134, 43-55. https://doi.org/10.1016/S0165-3806(01)00291-7

[41] Valiente, M. and Marin, O. (2010) Neuronal Migration Mechanisms in Development and Disease. Current Opinion in Neurobiology, 20, 68-78.

https://doi.org/10.1016/j.conb.2009.12.003

[42] Evsyukova, I., Plestant, C. and Anton, E.S. (2013) Integrative Mechanisms of Oriented Neuronal Migration in the Developing Brain. Annual Review of Cell and Developmental Biology, 29, 299-353. https://doi.org/10.1146/annurev-cellbio-101512-122400

[43] Campbell, K. and Gotz, M. (2002) Radial Glia: Multi-Purpose Cells for Vertebrate Brain Development. Trends in Neurosciences, 25, 235-238. https://doi.org/10.1016/S0166-2236(02)02156-2

[44] Kriegstein, A.R. and Noctor, S.C. (2004) Patterns of Neuronal Migration in the Embryonic Cortex. Trends in Neurosciences, 27, 392-399. https://doi.org/10.1016/j.tins.2004.05.001

[45] Marin, O., Valdeolmillos, M. and Moya, F. (2006) Neurons in Motion: Same Principles for Different Shapes? Trends in Neurosciences, 29, 655-661. https://doi.org/10.1016/j.tins.2006.10.001

[46] Doyle, A.D., Wang, F.W., Matsumoto, K. and Yamada, K.M. (2009) One-Dimensional Topography Underlies Three-Dimensional Fibrillar Cell Migration. The Journal of Cell Biology, 184, 481-490. https://doi.org/10.1083/jcb.200810041

[47] Wright, L.S., Prowse, K.R., Wallace, K., Linskens, M.H. and Svendsen, C.N. (2006) Human Progenitor Cells Isolated from the Developing Cortex Undergo Decreased Neurogenesis and Eventual Senescence following Expansion in Vitro. Experimental Cell Research, 312, 2107-2120. https://doi.org/10.1016/j.yexcr.2006.03.012

[48] Keenan, T.M., Nelson, A.D., Grinager, J.R., Thelen, J.C. and Svendsen, C.N. (2010) Real Time Imaging of Human Progenitor Neurogenesis. PLoS ONE, 5, e13187. 
https://doi.org/10.1371/journal.pone.0013187

[49] Anderson, L., Burnstein, R.M., He, X., Luce, R., Furlong, R., Foltynie, T., et al. (2007) Gene Expression Changes in Long Term Expanded Human Neural Progenitor Cells Passaged by Chopping Lead to Loss of Neurogenic Potential in Vivo. Experimental Neurology, 204, 512-524. https://doi.org/10.1016/j.expneurol.2006.12.025

[50] Grealishemail, S., Diguet, E., Kirkeby, A., Mattsson, B., Heuer, A., Bramoulle, Y., Van Camp, N., Perrier, A.L., Hantraye, P., Björklund, A. and Parmaremail, M. (2014) Human ESC-Derived Dopamine Neurons Show Similar Preclinical Efficacy and Potency to Fetal Neurons When Grafted in a Rat Model of Parkinson's Disease. Cell Stem Cell, 15, 653-665. https://doi.org/10.1016/j.stem.2014.09.017

[51] Shahbazi, E., Kiani, S., Gourabi, H. and Baharvand, H. (2011) Electrospun Nanofibrillar Surfaces Promote Neuronal Differentiation and Function from Human Embryonic Stem Cells. Tissue Engineering Part A, 17, 3021-3031. https://doi.org/10.1089/ten.tea.2011.0121

[52] den Braber, E.T., de Ruijter, J.E., Ginsel, L.A., von Recum, A.F. and Jansen, J.A. (1998) Orientation of ECM Protein Deposition, Fibroblast Cytoskeleton, and Attachment Complex Components on Silicone Microgrooved Surfaces. Journal of Biomedical Materials Research Part $A, 40,291-300$. https://doi.org/10.1002/(SICI)1097-4636(199805)40:2<291::AID-JBM14>3.0.CO;2-P

[53] den Braber, E.T., de Ruijter, J.E., Ginsel, L.A., von Recum, A.F. and Jansen, J.A. (1996) Quantitative Analysis of Fibroblast Morphology on Microgrooved Surfaces with Various Groove and Ridge Dimensions. Biomaterials, 17, 2037-2044. https://doi.org/10.1016/0142-9612(96)00032-4

[54] Dalby, M.J. (2005) Topographically Induced Direct Cell Mechanotransduction. Medical Engineering and Physics, 27, 730-742. https://doi.org/10.1016/j.medengphy.2005.04.005

[55] Smeal, R.M., Rabbitt, R., Biran, R. and Tresco, P.A. (2005) Substrate Curvature Influences the Direction of Nerve Outgrowth. Annals of Biomedical Engineering, 33, 376-382. https://doi.org/10.1007/s10439-005-1740-Z

[56] Dunn, G.A. and Heath, J.P. (1976) A New Hypothesis of Contact Guidance in Tissue Cells. Experimental Cell Research, 101, 1-14. https://doi.org/10.1016/0014-4827(76)90405-5

[57] Teixeira, A.I., McKie, G.A., Foley, J.D., Bertics, P.J., Nealey, P.F., et al. (2006) The Effect of Environmental Factors on the Response of Human Corneal Epithelial Cells to Nanoscale Substrate Topography. Biomaterials, 27, 3945-3954. https://doi.org/10.1016/j.biomaterials.2006.01.044

[58] Rajnicek, A., Britland, S. and McCaig, C. (1997) Contact Guidance of CNS Neurites on Grooved Quartz: Influence of Groove Dimensions, Neuronal Age and Cell Type. Journal of Cell Science, 110, 2905-2913. 